
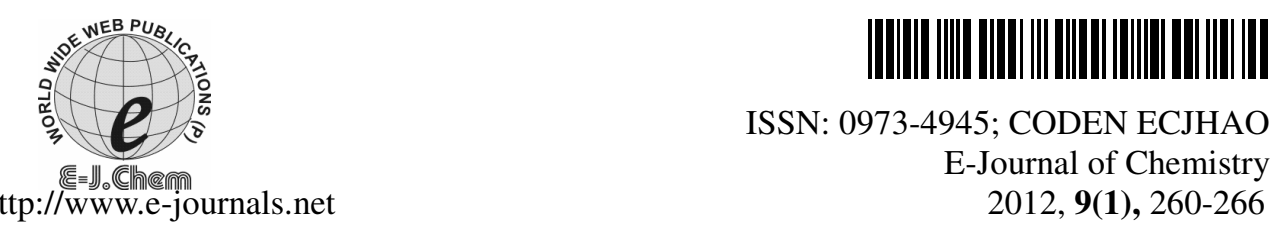

ISSN: 0973-4945; CODEN ECJHAO

E-Journal of Chemistry 2012, 9(1), 260-266

\title{
A Validated RP-HPLC Method for the Determination of Citrinin in Xuezhikang Capsule and other Monascus-Fermented Products
}

\author{
LI XUE-MEI ${ }^{\S *}$, SHEN XING-HAI ${ }^{\S}$, XUE LAN, $^{*}$ \\ DUAN ZHEN-WEN ${ }^{\S}$ and GUO SHU-REN \\ ${ }^{\S}$ Institute of Chemistry and Molecular Engineering \\ Peking University, Beijing, 100871, PR China \\ Beijing WBL Peking University Biotechnology Co., Ltd., \\ Beijing, 100080, PR China \\ xuemei0309@126.com
}

Received 11 April 2011; Accepted 2 July 2011

\begin{abstract}
Citrinin is a toxic product usually produced during the Monascus fermentation. The presence of citrinin in xuezhikang capsule has been a concern due to its ingredient which is derived from monascus-fermented rice. A rapid and sensitive RP-HPLC method with fluorescence detection at $\lambda_{\mathrm{ex}}=331 \mathrm{~nm}$ and $\lambda_{\mathrm{em}}=500 \mathrm{~nm}$ for analysis of citrinin in Monascus-fermented products was developed to analyze citrinin in Monascus-fermented products. The chromatography was performed with mobile phase containing acidified water and acetonitrile. The calibration curve was linear $(r=0.9999)$ over a range of $0.0107-0.537 \mu \mathrm{g} / \mathrm{mL}$. The limit of detection (LOD) and the limit of quantitation (LOQ) were $0.187 \mathrm{ng} / \mathrm{mL}$ and $0.6 \mathrm{ng} / \mathrm{mL}$ respectively. The analysis of xuezhikang capsules using the developed method suggested that the product does not contain detectable citrinin and the result has been further confirmed using independent LC-MS/MS analysis. The proposed method has also been applied to analyze 11 samples of other Monascus-fermented products. The results suggested that there were no detectable citrinin in 4 of the 11 samples, however citrinin with the levels between $0.10-594 \mathrm{ng} / \mathrm{kg}$ has been detected in the other 7 samples. It indicates that the proposed method can also be applied to carry out the quantitative detection of citrinin for other Monascus-fermented products.
\end{abstract}

Keywords: HPLC, LC-MS/MS, Citrinin, Xuezhikang capsule, Monascus

\section{Introduction}

Cintrinin, a toxic product of secondary metabolite of fungi, such as Aspergillus, Penicillium, and Monascus species, is known to lead to serious health problems ${ }^{1}$. Generally, citrinin is 
present in a trace concentration (0.1-500 mg/kg), compared with other Monascus metabolites. Citrinin $\left[\mathrm{C}_{13} \mathrm{H}_{14} \mathrm{O}_{5}\right.$, IUPAC: $(3 R, 4 S)$-4,6-dihydro-8-hydroxy-3, 4, 5-trimethyl-6oxo-3H-2-benzopyran-7-carboxylic acid; CAS No.: 518-75-2] (Figure 1), is an acidic lemon-yellow crystal with maximal UV absorption at $250 \mathrm{~nm}$ and $333 \mathrm{~nm}$ (in methanol), melting at $172{ }^{\circ} \mathrm{C}$. The reversed-phase HPLC with sensitive fluorescence detection is the most effective method for the determination of citrinin ${ }^{2-4}$. According to the Chinese national standard method for the determination of citrinin in Monascus-fermented products, an ultrasonic-extraction with toluene-ethyl acetate-formic acid $=7: 3: 1$ is used for the pretreatment of the Monascus-fermented products ${ }^{5}$.

In this work, we developed a selective and sensitive PR-HPLC method that can conveniently detect the lowest possible amount of $0.187 \mathrm{ng} / \mathrm{mL}$ citrinin, which is more sensitive than the recent report of $0.5 \mathrm{ng} / \mathrm{mL}$ detection limit ${ }^{4}$. Further, how much citrinin is lost in the pretreatment process was investigated by recovery studies.<smiles>C=CC1=C(C)C(=O)C(C(=O)O)=C(O)C2=CO[C@H](C)[C@H](C)C2=C1C(=O)O</smiles>

Figure 1. Chemical structures of citrinin isomers

\section{Experimental}

Citrinin was purchased from Sigma (Shanghai, China). Xuezhikang capsule (Xuezhikang) was produced by Beijing WBL Peking University Biotechnology Co., Ltd., China. The commercially available Monascus-fermented products were obtained from the local market. Acetonitrile and methanol were of HPLC grade and all other reagents were analytical grade.

\section{Instrumentation}

The chromatographic system consisted of Shimadzu LC-20A separations module and a Shimadzu RF-20A Fluorescence Detector. Fluorescence detection was performed with the Shimadzu RF-20A fluorescence detector with $\lambda_{\mathrm{ex}}=331 \mathrm{~nm}$ and $\lambda_{\mathrm{em}}=500 \mathrm{~nm}$. A column of Aichrombond-AQ $\mathrm{C}_{18}(250 \mathrm{~mm} \times 4.6 \mathrm{~mm}$ i.d., $5 \mu \mathrm{m})$ was used and the column temperature was set at $25^{\circ} \mathrm{C}$. An Agilent 1200 HPLC separation system was used to deliver samples into a Bruker micrOTOF-QII mass spectrometer.

\section{Preparation of standard solution}

The standard stock solution was prepared by dissolving accurately weighed $5.37 \mathrm{mg}$ of citrinin standard in $100 \mathrm{~mL}$ of methanol (final concentration, $53.7 \mu \mathrm{g} / \mathrm{mL}$ ). Different calibration standards ranging from $0.01074,0.0537,0.1074,0.2685$ and $0.537 \mu \mathrm{g} / \mathrm{mL}$ were prepared by appropriate dilution of standard stock solution with methanol.

\section{Preparation of sample solution}

An assay sample (Xuezhikang or other Monascus-fermented products) was milled and passed through 80 -mesh sieve. Accurately weighed $1.5 \mathrm{~g}$ of sample powder was transferred to a $15 \mathrm{~mL}$ PTEE centrifuge tube, and ultrasonic-extracted with $10 \mathrm{~mL}$ toluene-ethyl acetateformic acid = 7:3:1 for $20 \mathrm{~min}, 3$ times. The combined extract solution was centrifuged to remove undissolved residue and the supernatant was evaporated under vacuum to afford citrinin-enrichment crude extract. The crude extract was dissolved with $10 \mathrm{~mL}$ methanol and filtered through a $0.45 \mu \mathrm{m}$ membrane filter for detection. 


\section{Chromatographic conditions}

The mobile phase A was acetonitrile and mobile phase B was acidified water $(\mathrm{pH} 2.5$ adjusted with phosphoric acid). The gradient elution program has been developed and optimized for better, accurate and consistent results. The gradient eluting system was shown in Table 1. The injection volume was $20 \mu \mathrm{L}$ and the flow rate was $1.0 \mathrm{~mL} / \mathrm{min}$.

Table 1. Gradient elution system in HPLC

\begin{tabular}{ccc}
\hline Time, $\min$ & $\mathrm{A}, \%$ & $\mathrm{~B}, \%$ \\
\hline 0 & 53.5 & 46.5 \\
14 & 53.5 & 46.5 \\
15 & 100 & 0 \\
22 & 100 & 0 \\
23 & 53.5 & 46.5 \\
30 & 53.5 & 46.5 \\
\hline
\end{tabular}

\section{Results and Discussion}

The applied chromatographic conditions permitted a good resolution of citrinin in standard solution (A) and in sample solution (B) (Figure 2). The LC method was validated for the parameters reported below.

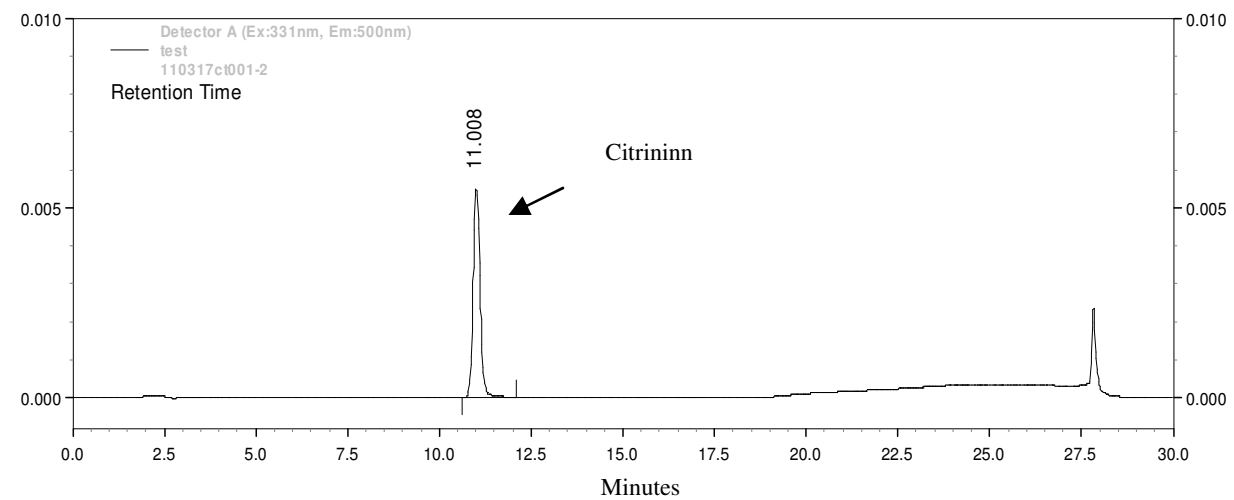

Figure 2(A). Typical chromatogram of citrinin

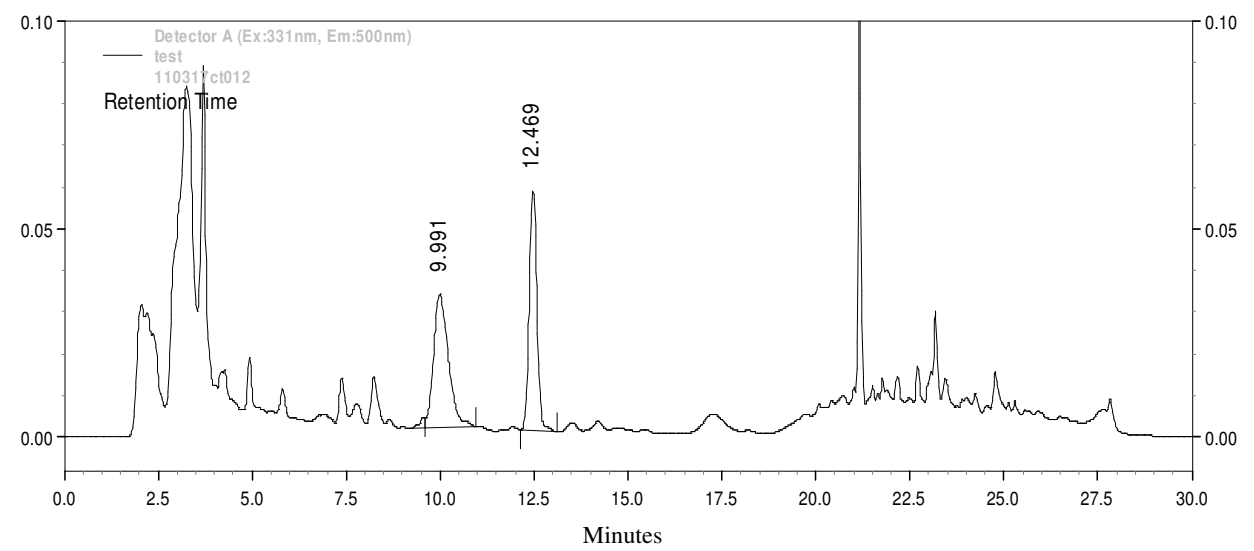

Figure 2(B). Typical chromatogram of Xuezhikang 


\section{Linearity}

The calibration standards were chromatographed using the mobile phase, and the linearity of peak areas versus corresponding concentrations was studied from $0.01074-0.537 \mu \mathrm{g} / \mathrm{mL}$ for citrinin. A linear response was observed over the examined concentration range. The results are tabulated in Table 2.

Table 2. Results of the data analysis for the linearity of citrinin

\begin{tabular}{cc}
\hline Parameters & HPLC \\
\hline Concentration range, $\mu \mathrm{g} / \mathrm{mL}$ & $0.01074-0.537$ \\
Regression equation & $\mathrm{Y}=34335.93 X-1363.90$ \\
Correlation coefficient $(\mathrm{r})$ & 0.9999 \\
\hline
\end{tabular}

\section{Limit of detection and limit of quantitation}

The limit of quantitation (LOQ) was the lowest concentration of the sample assayed when the signal/noise ratio was at least 10:1. The limit of detection (LOD) was defined as a signal/noise ratio of $3: 1$. The LOQ and LOD were found to be $0.6 \mathrm{ng} / \mathrm{mL}$ and $0.187 \mathrm{ng} / \mathrm{mL}$ respectively.

\section{Precision and recovery}

The precision of the method was evaluated by analyzing the standard solution of $0.1074 \mu \mathrm{g} / \mathrm{mL}$ citrinin with five replicates. The results are shown in Table 3.

Table 3. The result of precision assay

\begin{tabular}{cccccc}
\hline No. & 1 & 2 & 3 & 4 & 5 \\
\hline Peak area of citrinin & 71482 & 71218 & 71413 & 71413 & 71479 \\
RSD, \% & & & 0.15 & & \\
\hline
\end{tabular}

The recovery tests were conducted to evaluate the extraction method aforementioned. They were performed by adding known amounts of standard stock solutions to the xuezhikang samples and preparing solutions according to the preparation of sample solution. The percentage of recovery was calculated by comparing the determined amount of citrinin standard with the added amount. The calculation of \% recovery is tabulated in Table 4.

Table 4. The result of recovery analysis

\begin{tabular}{cccccccc}
\hline No. & $\begin{array}{c}\text { Weight of } \\
\text { Xuezhikang, } \\
\mathrm{g}\end{array}$ & $\begin{array}{c}\text { Citrinin in } \\
\text { Xuezhikang, } \\
\mu \mathrm{g}\end{array}$ & $\begin{array}{c}\text { Spiked } \\
\text { Citrinin, } \\
\mu \mathrm{g}\end{array}$ & $\begin{array}{c}\text { Calculated } \\
\text { Citrinin, } \\
\mu \mathrm{g}\end{array}$ & $\begin{array}{c}\text { Recovery, } \\
\%\end{array}$ & $\begin{array}{c}\text { Average } \\
\text { Recovery, } \\
\%\end{array}$ & $\begin{array}{c}\text { RSD, } \\
\%\end{array}$ \\
\hline 1 & 1.5029 & undetected & 5.37 & 5.15 & 95.90 & & \\
2 & 1.5037 & undetected & 5.37 & 5.18 & 96.46 & & \\
3 & 1.5031 & undetected & 5.37 & 5.22 & 97.21 & & \\
4 & 1.5050 & undetected & 5.37 & 5.19 & 96.65 & & \\
5 & 1.5009 & undetected & 5.37 & 5.24 & 97.60 & 96.68 & 0.64 \\
6 & 1.5068 & undetected & 5.37 & 5.17 & 96.28 & & \\
\hline
\end{tabular}

Detection of citrinin in Xuezhikang and other Monascus-fermented products 
Natural occurrence of citrinin in Xuezhikang and other Monascus-fermented products (including red yeast rice and Monascus pigment) was studied. A total of 18 samples were analyzed by HPLC for citrinin. The results revealed that 11 samples were negative for containing citrinin and 7 samples were positive for containing citrinin with the levels between 0.10 and $594 \mu \mathrm{g} / \mathrm{kg}$ (Table 5).

Table 5. Detection results of citrinin in 18 samples

\begin{tabular}{cccc}
\hline No. & Sample & Lot No. & Content of Citrinin, $\mu \mathrm{g} / \mathrm{kg}$ \\
\hline 1 & Xuezhikang & 20100811 & undetected \\
2 & Xuezhikang & 20100901 & undetected \\
3 & Xuezhikang & 20101108 & undetected \\
4 & Xuezhikang & 20101211 & undetected \\
5 & Xuezhikang & 20110103 & undetected \\
6 & Xuezhikang & 20110111 & undetected \\
7 & Xuezhikang & 20110201 & undetected \\
8 & Red yeast rice 1 & 20100820 & 0.97 \\
9 & Red yeast rice 2 & 20100612 & 1.32 \\
10 & Monascus pigment powder 1 & 20100817 & 594 \\
11 & Monascus pigment powder 2 & 20100718 & 122 \\
12 & Functional red yeast rice powder 1 & 20090627 & 0.10 \\
13 & Functional red yeast rice powder 2 & 20090916 & 4.04 \\
14 & Functional red yeast rice powder 3 & 20090810 & 5.41 \\
15 & Red yeast rice health food 1 & 20100320 & undetected \\
16 & Red yeast rice health food 2 & 20100412 & undetected \\
17 & Red yeast rice health food 3 & 20100501 & undetected \\
18 & Red yeast rice health food 4 & 20100530 & undetected \\
\hline
\end{tabular}

LC-MS/MS analysis

Chromatographic separation was modified based on the HPLC condition. The same column was used and the mobile phase A was acetonitrile and mobile phase B was $0.4 \%$ formic acid. The gradient eluting system is shown in Table 6 . The injection volume was $20 \mu \mathrm{L}$. The flow rate was $1.0 \mathrm{~mL} / \mathrm{min}$, with the flow rate split down to $0.25 \mathrm{~mL} / \mathrm{min}$ into the MS source.

Table 6. Gradient elution system in LC-MS/MS detection

\begin{tabular}{ccc}
\hline Time, $\min$ & $\mathrm{A}, \%$ & $\mathrm{~B}, \%$ \\
\hline 0 & 45 & 55 \\
16 & 45 & 55 \\
17 & 100 & 0 \\
25 & 100 & 0 \\
26 & 45 & 55 \\
35 & 45 & 55 \\
\hline
\end{tabular}


MS analysis was performed by employing the ESI positive ion mode in mass range of 50-2000. High purity nitrogen was used as nebulizer and auxiliary gas. The mass parameters were optimized to the following values: hexapole $\mathrm{R}_{\mathrm{f}}(200.0 \mathrm{VPP})$; collision $\mathrm{R}_{\mathrm{f}}(100.0 \mathrm{VPP})$; pre pulse storage $(5.0 \mu \mathrm{s})$; collision energry $(7.0 \mathrm{eV})$; quadrupole ion energy $(5.0 \mathrm{eV})$; nebulizer $(0.8$ bar $)$; dry gas $(5.0 \mathrm{~L} / \mathrm{min})$; dry temperature $\left(180{ }^{\circ} \mathrm{C}\right)$. The LC-MS/MS chromatograms for the citrinin and xuezhikang are displayed in Figure 3 and 4 . In the LC-MS/MS analysis of xuezhikang, it is supposed to be no peak detected at the retention time of citrinin.

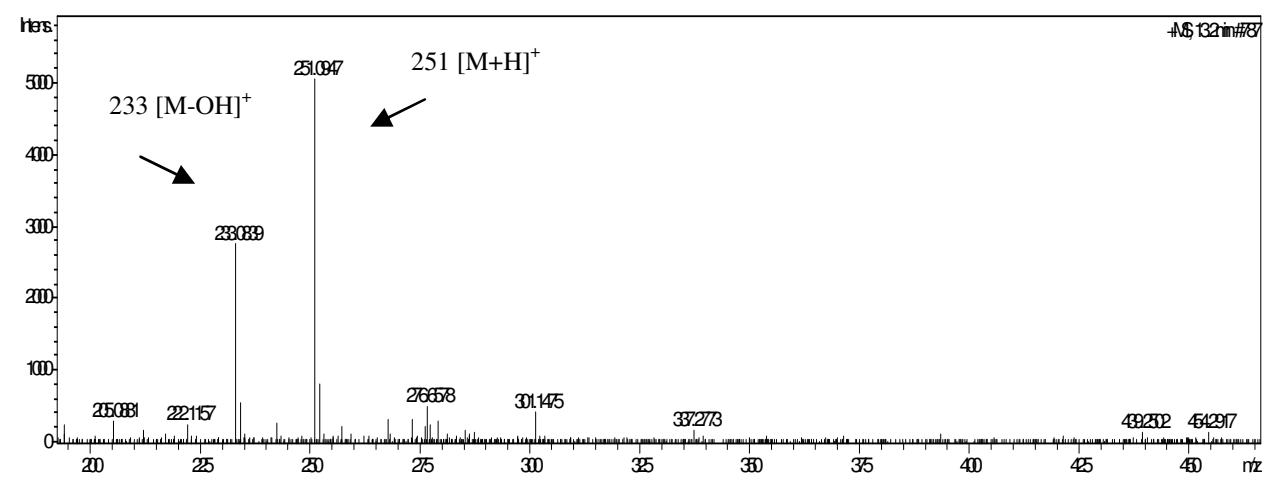

Figure 3. Full-scan product ion spectrum for citrinin

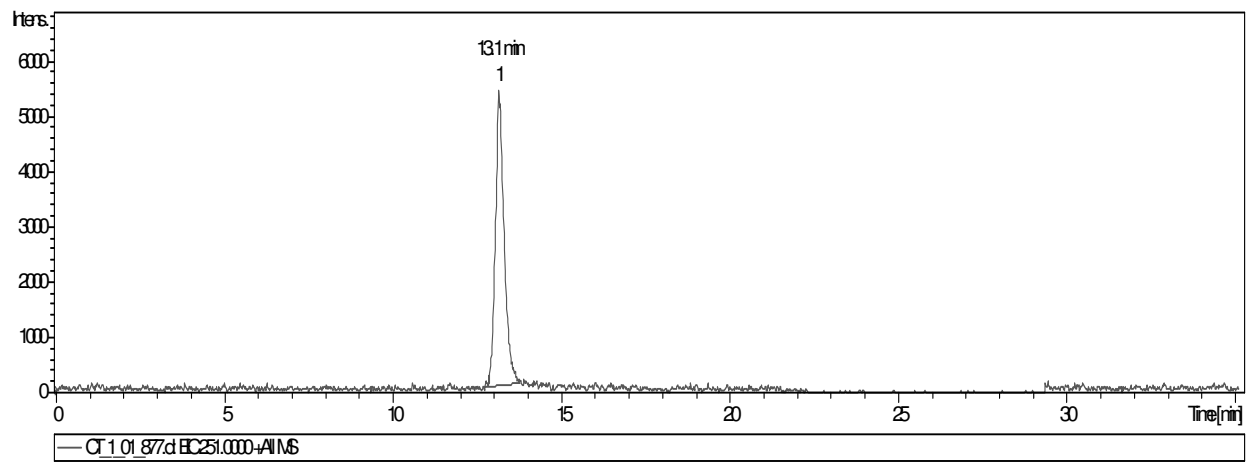

Figure 4 (A). EIC $\left(\mathrm{m} / z 251[\mathrm{M}+\mathrm{H}]^{+}\right)$chromatogram of citrinin

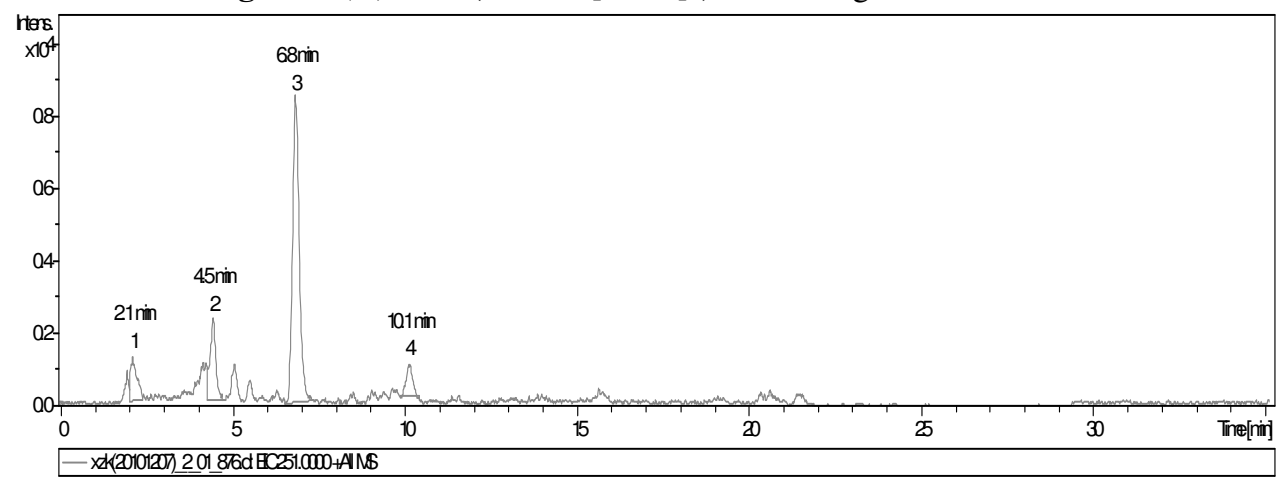

Figure 4 (B). EIC $\left(\mathrm{m} / \mathrm{z}, 251[\mathrm{M}+\mathrm{H}]^{+}\right)$chromatogram of xuezhikang 


\section{Conclusion}

The proposed reverse phase HPLC method has been evaluated over the linearity, precision and recovery and proved to be convenient and effective for the detection of citrinin in Monascusfermented products as well as other routine quality control procedure. Under the reported HPLC conditions, a detection limit of citrinin achieved was as low as $0.187 \mathrm{ng} / \mathrm{mL}$. Quantitative analysis of citrinin in xuezhikang using the proposed protocol suggested that there were no detectable citrinin and the result has been double-confirmed by LC-MS/MS. The method can also be applied for routine quality control analysis of citrinin in Monascus-fermented products.

\section{Acknowledgment}

The authors are thankful to funds provided by the National Important Special Foundation of the New Drug Development, China (No.2008ZX09202-007). We also thank Liu Hai-ling from analytical and testing center, Beijing Normal University, China, for LC-MS/MS analysis.

\section{References}

1. Bennett J W and Klich M, Clin Microbiol Rev., 2003, 16(3), 497-516.

2. $\quad \mathrm{Xu} \mathrm{B,} \mathrm{Jia} \mathrm{X,} \mathrm{Gu} \mathrm{L} \mathrm{and} \mathrm{Sung} \mathrm{C,} \mathrm{Food} \mathrm{control.,} \mathrm{2006,} \mathrm{17(4),} \mathrm{271-285.}$

3. Franco CM, Fente CA, Vazquez B, Lallaoui L, Prognon P and Mahuzier G, $J$ Chromatogr A., 1996, 723(1), 69-75.

4. Zheng Y, Xin Y and Guo Y, Food Chem., 2009, 113, 705-711.

5. Determination of citrinin in Monascus products, Chinese national standard (GB/T., 5009, 222-2008. 


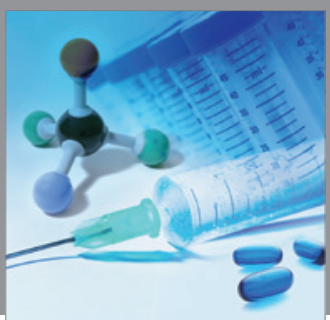

International Journal of

Medicinal Chemistry

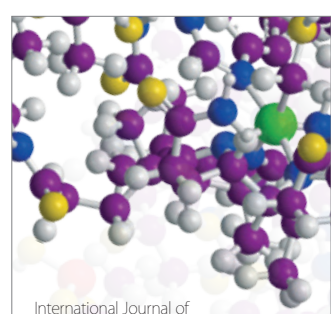

Carbohydrate Chemistry

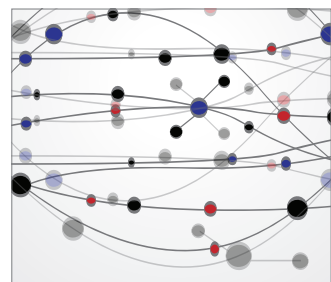

The Scientific World Journal
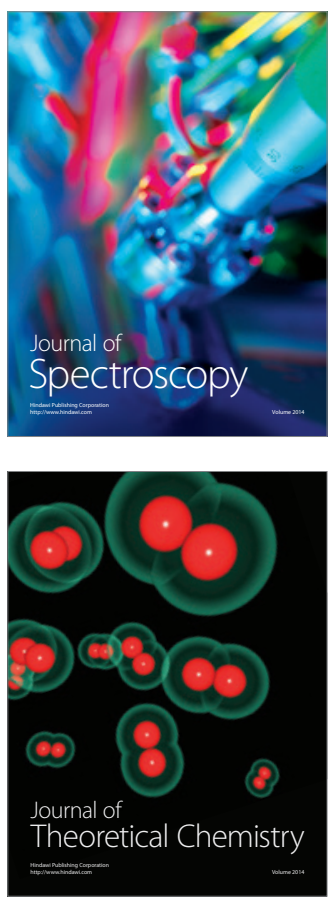
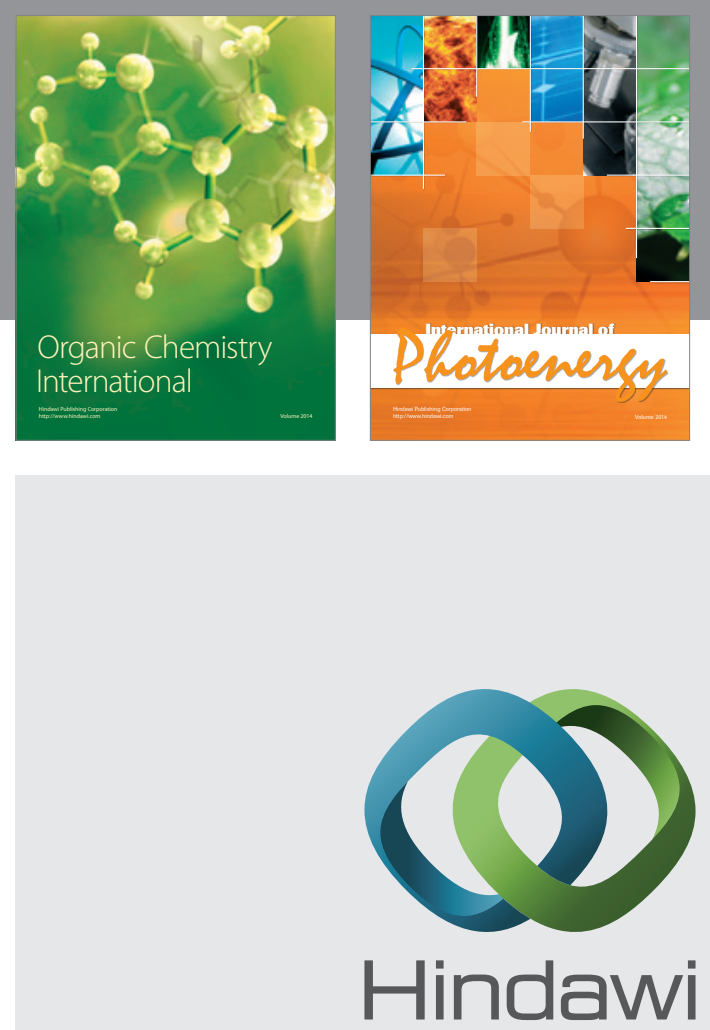

Submit your manuscripts at

http://www.hindawi.com
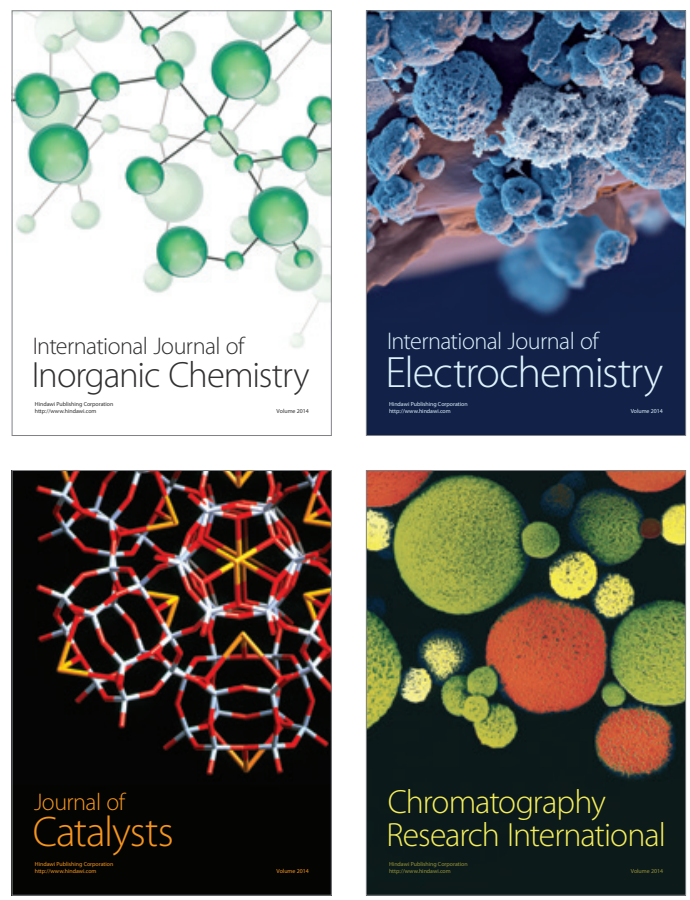
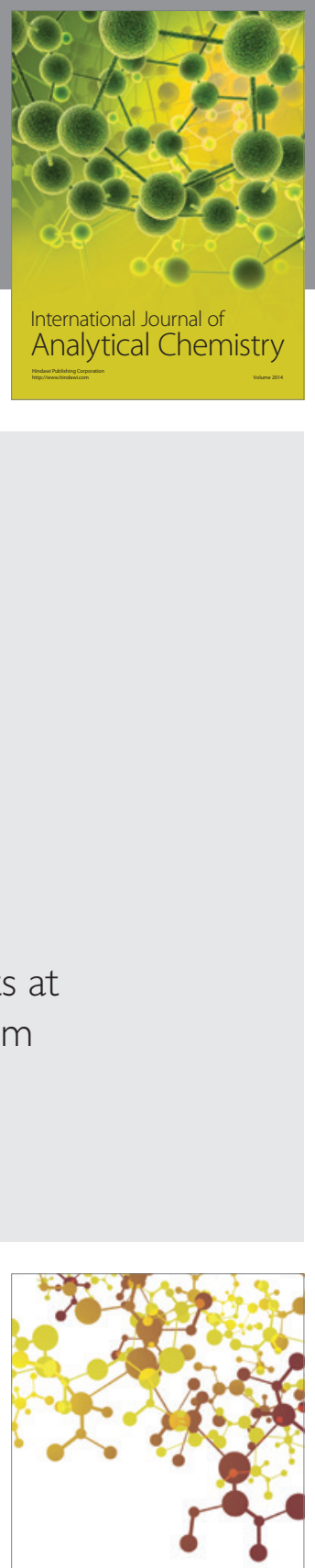

Journal of

Applied Chemistry
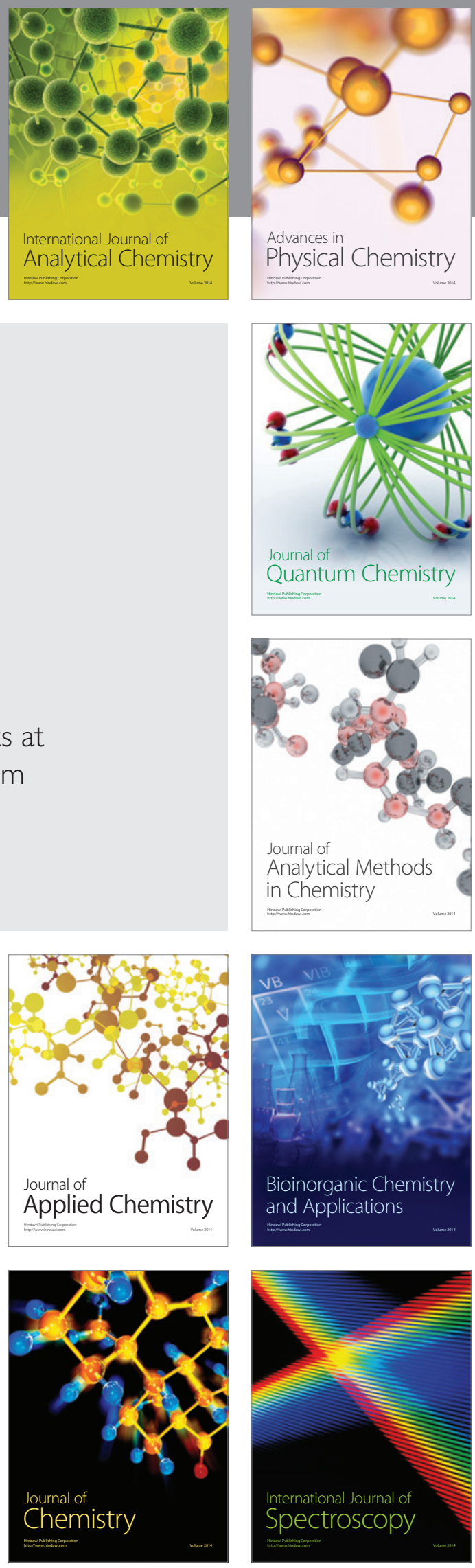